\title{
DIVERSITY AND DISTRIBUTION OF AVIFAUNA OF LAKKAVALLI RANGE FOREST, BHADRA WILDLIFE SANCTUARY, WESTERN GHAT, INDIA
}

\author{
M.N. Harisha and B.B. Hosetti \\ Department of Post Graduate Studies and Research in \\ Applied Zoology and Wildlife Management \\ Kuvempu University, Jnana Sahyadri \\ Shankaraghatta-577451, Shimoga, Karnataka, India \\ E-mail: basling@yahoo.co.in
}

\begin{abstract}
A total of 132 species of birds belonging to 34 families under 11 orders were recorded during the study period between April 2007 to March 2008 in the Lakkavalli range forest, Bhadra Wildlife Sanctuary, Western Ghat, Karnataka, India. There were 112 resident, 12 winter migratory, 7 local migratory and one summer migratory birds, respectively. Among the birds recorded in the study area, about $49 \%$ were insectivores and other dominating types included mixed diet $25 \%$, omnivores $11 \%$ carnivores $9 \%$, granivores $3 \%$ and frugivores $3 \%$, respectively. Species richness was maximum in the early winter and relatively less in other seasons.
\end{abstract}

Key words: Western Ghat, Lakkavalli, avifauna diversity, landscape.

\section{INTRODUCTION}

Birds are among the best monitors of environmental changes and have been used to evaluate the environment throughout the history as 'biomonitors' and; the changes in their population, behavior patterns and reproductive ability have most often been used to examine the long term affects of habitat fragmentation. Hence they are the good indicators of ecological status of any given ecosystem (Bilgrami 1995). Forests attract a large number of avifauna because of the habitat suitability for most of them. This especially include the birds that are associated with the vegetation, and for most, the existence of trees is vital to their life cycle. Birds show different levels of interest to various stands depending on the age of the stands.
The bird species composition is highly related to the forest's vegetation structure. The diversity of birds, and in particular the native species, is positively correlated with increasing structural complexity of the vegetation. Also a seasonal change in species diversity of birds occurs in forests due to their foraging behaviour (Robertson and Hackwell 1995). The present study was undertaken to assess the pattern of distribution and diversity of avifauna in the Westernghat, India.

\section{STUDY AREA}

Lakkavalli range forest encompasses an area of $229.65 \mathrm{sq} \mathrm{km}$ and is one of the largest range forest in the limits of Bhadra Wildlife Sanctuary spanning between $13^{\circ} 22^{\prime}$ to $13^{\circ} 47^{\prime} \mathrm{N}$ latitude; 
$75^{\circ} 29^{\prime}$ to $75^{\circ} 45^{\prime}$ E longitude (Map 1). Lakkavalli range forest is located $30 \mathrm{~km}$ south of Shimoga city with a varied type of vegetation encompassing dry mixed deciduous forest, moist mixed deciduous forest and sparsely spread semi-evergreen forest. Northern part of the forest range adjoins the Bhadra Reservoir. The terrain in the reserve is undulating with valleys surrounded by steep hills. Temperature within the sanctuary vary from $9^{\circ}$ to $35^{\circ} \mathrm{C}$ and mean annual rainfall varies from 1200 to $2600 \mathrm{~mm}$ dominated by southwest monsoon during July to September. The study area has been divided into 6 line transects each measures upto $500 \mathrm{~m}$ in length and their width depending upon the vegetation pattern $(20 \mathrm{~m}$ in plantation, $30 \mathrm{~m}$ in mixed forest patches).

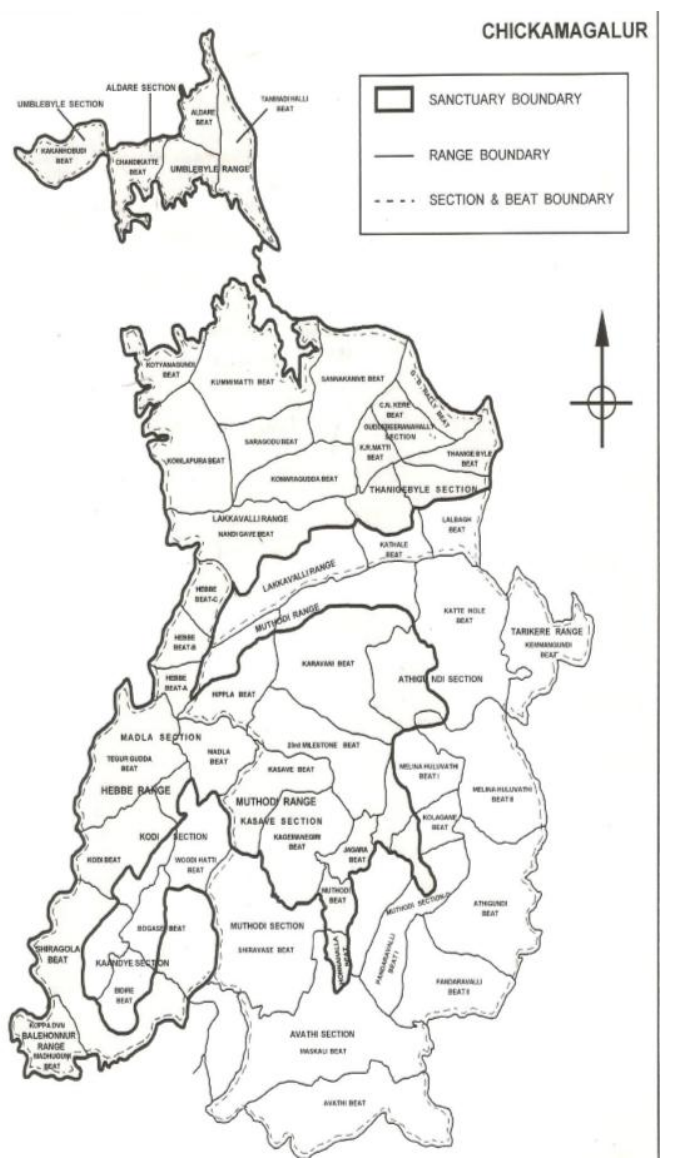

Map. 1. Location map of the study area.

\section{MATERIAL AND METHODS}

The study was conducted during the period April 2007 to March 2008. Bird species were assessed in the representative plots using direct and line transect counting methods. Six line transects were set up, which were approximately $500 \mathrm{~m}$ in length and 20 to $30 \mathrm{~m}$ width, passing through the four landscape element types. The transect line was walked at a constant pace for approximately halfan-hour. Observations were taken between 0730 to $1100 \mathrm{hr}$ in the morning and $1430 \mathrm{hr}$ to $1800 \mathrm{hr}$ in the afternoon, depending on the season, when birds were most active. The birds were identified using Olympus binoculars (10x50) and field guides of Ali and Ripley (1983) and Grimmett et al. (2001). The nomenclature followed here is Manakadan and Pittie (2001). For the interpretation of collected data the year was divided into six seasons: (i) Spring- February and March, (ii) Summer- April and May, (iii) Early monsoon- June and July, (iv) Late monsoon- August and September, (v) Early winter- October and November, (vi) Late winterDecember and January. Furthermore, each transect line was also categorized in one of the four landscape elements, viz. bamboo vegetation $\left(13^{0} 39.040^{\prime} \mathrm{N}\right.$ latitude and $75^{0} 39.389^{\prime} \mathrm{E}$ longitude, LSE 1); teak plantation $\left(13^{0} 39.620^{\prime} \mathrm{N}\right.$ latitude and $75^{0} 39.911^{\prime}$ E longitude, LSE 2); dry deciduous forest $\left(13^{0} 37.494^{\prime} \mathrm{N}\right.$ latitude and $75^{0} 39.139^{\prime} \mathrm{E}$ longitude, LSE 3); and moist deciduous forest $\left(13^{0} 36.915^{\prime} \mathrm{N}\right.$ latitude and $75^{0} 39.171^{\prime} \mathrm{E}$ longitude, LSE 4) and also the frequency of sighting of the birds in these habitats were worked out.

\section{Data Analysis}

The data were subjected to detail analysis which included Simpson index, Shannon Weiner's index, Species richness index, and Species evenness index. 
1. Shannon index of diversity $\left(\mathrm{H}^{1}\right)$ :

$$
\mathrm{H}^{1}=-\sum \text { pi ln pi }
$$

Where, 'pi' is the proportion of the $\mathrm{i}^{\text {th }}$ species to total abundance value.

2. Evenness index: To calculate whether species are distributed evenly across seasons and across landscapes elements, evenness index was determined by the equation

\section{$E=H^{\prime} / \ln S$}

Where, $\mathrm{H}^{\prime}$ is Shannon-Wiener's diversity index and $\mathrm{S}$ is Species richness.

3. Shannon-Wiener's equitability index (J):The value obtained indicates the chances of occurrence of individual species in one sample. It was calculated using the formula.

\section{$\mathbf{J}=\mathbf{H}^{\prime} / \ln \mathbf{S}$}

Where, $\mathrm{H}^{\prime}$ is Shannon-Wiener's diversity index.

4. Standard deviation ( $\sigma)$ : Each individual deviation is symbolized by $\mathrm{x}_{1}$ with $\mathrm{n}$ numbers in the set, the standard deviation is given by the formula

$$
\sigma=\left[\sqrt{ } \Sigma\left(\mathbf{x}_{1}^{2}\right) / \mathbf{n}\right]
$$

\section{RESULTS}

\section{Occurrence of Birds}

During the present study, a total of 132 species of birds belonging to 34 families under 11 orders were recorded of which 112 species were resident, 12 winter migratory, 7 local (resident) migratory and 1 summer migratory bird. The total checklist, which also includes bird species encountered outside the transect. In the present study the bird species are classified into four groups based on the observation. Among these bird species 60 are common, 32 uncommon, 24 fairly common and 16 are rare species. Birds were also classified into 6 groups based on their food preference. Among these bird species 66 were Insectivorous, 14 omnivorous, 12 carnivorous, 6 frugi-nectariinsectivorous, 1 fruigi-grani-insectivorous and 4 granivorous, 2 grani-insectivorous, 8 granifruigivorous, 4 fruigivorous, and 15 fruigiinsectivorous. The vultures were not encountered and wetland birds were not recorded in the present study.

Species richness for six study sites were also calculated, which revealed highest for early winter (102), followed by summer (96), spring (90) and late winter (85) and lowest (55) for late mansoon (Table 1). Landscape elements wise species richness was highest in the LSE 4 (84) followed by LSE 3 (67), LSE 2 (48) and lowest in LSE 1 (40) (Table 2). In case of landscape elements, the number of individual of bird species were found to be maximum in LSE 4 followed by the LSE 3 and LSE 2 and minimum in LSE 1, where the dominant individual species were as follows: Purple-rumped sunbird, purple sunbird, spotted dove, hill myna and Malabar parakeet (Table 2). While the number of individuals for seasons were found to be maximum in summer followed by early winter and spring, and minimum in late monsoon, where the species dominated were, Purple-rumped sunbird, purple sunbird, Malabar parakeet, and spotted dove, etc. (Table 1).

In case of different landscape elements, the standard deviation of hill myna was higher that is 5.3 followed by Malabar parakeet (3.3), purple rumped-sunbird (3.2) and plum-headed parakeet (2.8), etc. In case of different seasons, the standard deviation of hill myna was higher i.e. 4.9, followed by jungle babbler (4.6) and purple-rumped sunbird (4.5), respectively. 
Table 1. Season-wise species richness, diversity indices, evenness and equitability index for birds of Lakkavalli state forest, Chikmagalur for the year April 2007 to March 2008.

\begin{tabular}{|l|c|c|c|c|c|c|}
\hline \multicolumn{1}{|c|}{ Seasons } & Summer & $\begin{array}{c}\text { Early } \\
\text { monsoon }\end{array}$ & $\begin{array}{c}\text { Late } \\
\text { monsoon }\end{array}$ & $\begin{array}{c}\text { Early } \\
\text { winter }\end{array}$ & $\begin{array}{c}\text { Late } \\
\text { winter } \\
\text { Spring }\end{array}$ \\
\hline Species Richness (S) & 96 & 70 & 55 & 102 & 85 \\
\hline Total number of Individuals (N) & 488 & 365 & 308 & 462 & 369 & 440 \\
\hline Shannon diversity index $\left(\mathrm{H}^{1}\right)$ & 4.02 & 3.75 & 3.55 & 4.10 & 3.96 & 3.97 \\
\hline Evenness index (E) & 0.58 & 0.61 & 0.63 & 0.59 & 0.62 & 0.59 \\
\hline Shannon equitability index (J) & 0.88 & 0.88 & 0.89 & 0.89 & 0.89 & 0.88 \\
\hline
\end{tabular}

Summer- April and May, Early monsoon- June and July, Late monsoon- August and September

Early winter- October and November, Late winter- December-January, Spring- February-March

Table 2. Landscape element wise species richness, diversity indices, evenness and equitability index for birds of Lakkavalli state forest, Chikmagalur for the year April 2007 to March 2008.

\begin{tabular}{|l|c|c|c|c|}
\hline \multicolumn{1}{|c|}{ Landscape types } & LSE 1 & LSE 2 & LSE 3 & LSE 4 \\
\hline Diversity indices & & & & \\
\hline Species Richness (S) & 40 & 48 & 67 & 84 \\
\hline Total number of Individuals (N) & 54 & 67 & 111 & 154 \\
\hline Shannon diversity index (H $\left.{ }^{1}\right)$ & 3.53 & 3.73 & 3.97 & 4.11 \\
\hline Evenness index (E) & 0.85 & 0.87 & 0.79 & 0.73 \\
\hline Shannon equitability index (J) & 0.96 & 0.96 & 0.95 & 0.93 \\
\hline
\end{tabular}

LSE 1- Bamboo vegetation, LSE 2- Teak plantation, LSE 3 - Dry deciduous forest, LSE 4- Moist deciduous forest

\section{Diversity Indices}

By season wise, the maximum Shannon Index of Diversity, Evenness index and Equitability, were found in early winter, i.e. 4.10, 0.89, respectively; however, the evenness index was minimum in early winter (0.59). Shannon diversity index was minimum in the late monsoon i.e. 3.55; however, the evenness index was maximum in late monsoon i.e. 0.63. Evenness index was found to be minimum in the summer, i.e. 0.58 (Table 1 and Fig. 1).

Landscape element wise, the maximum Shannon diversity index $\left(\mathrm{H}^{1}\right)$, was found in LSE 4 (moist deciduous forest), i.e. 4.11; however, Evenness index (E) and Shannon equitability index (J) were minimum in the LSE 4, i.e., 0.73, 0.93, respectively. Shannon diversity index was minimum in the LSE 1 (bamboo vegetation), i.e. 3.5; however, Evenness index, Shannon equitability index were maximum in LSE 1, i.e., $0.85,0.96$, respectively (Table 2 and Fig. 2). Two Red Listed species (after Birdlife International 2001) were recorded from the Lakkavalli range forest, while 6 species endemic to Western Ghats, were also recorded. In case of endemic species, i.e. Rufous Babbler and in case of threatened species i.e. Malabar pied hornbill were not sighted from 
the teak plantation (LSE 2) and bamboo vegetation (LSE 1).

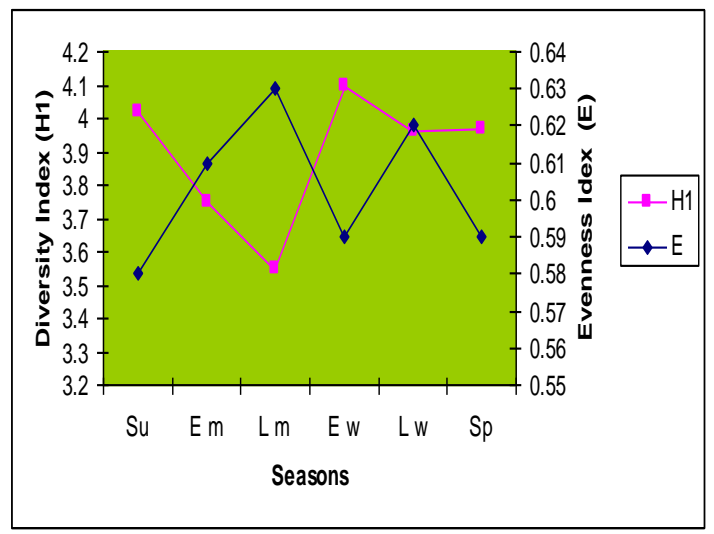

Fig. 1. Diversity index $\left(\mathrm{H}^{1}\right)$ and evenness index (E) of birds in different seasons in the Lakkavalli state forest (April 2007 - March 2008).

Su- Summer, Em- Early monsoon, Lm- Late monsoon, Ew- Early winter, Lw- Late winter, Sp- Spring

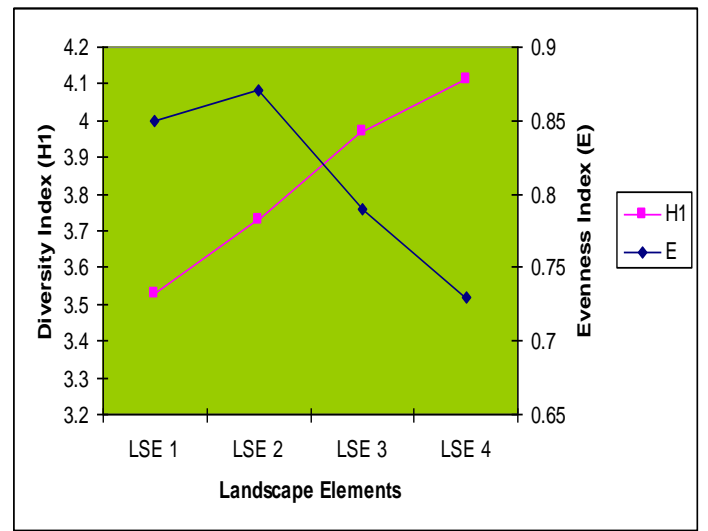

Fig. 2. Diversity index $\left(\mathrm{H}^{1}\right)$ and evenness index (E) of birds in different landscape elements or vegetation in the Lakkavalli state forest (April 2007-March 2008).

LSE 1- Bamboo vegetation, LSE 2- Dry deciduous forest, LSE 3- Teak plantation, LSE 4- Moist deciduous forest

Community structure of the birds was dominated by insectivorous species (49\%). Birds with mixed diet constituting of fruit, as well as grainy, nectar, and insects were the next ones contributing $25 \%$ of the total avifauna, while omnivorous, carnivorous, fruigivorous and grainyvorous contributed $11 \%$, $9 \%, 3 \%$ and $3 \%$, respectively with almost the same dominance as the mixed diet of birds.

\section{DISCUSSION}

Since major habitat transformation is a significant factor underlying erosion of diversity. It is important to understand the pattern of diversity of various taxonomic groups across different vegetation types. Very little is known about the diversity dispersion across different vegetation types that constitute an intricate mosaic in this hill region of Western Ghats (Daniel et al. 1992). The species richness, and diversity of birds in the Lakkavalli range forest were comparable with the other ecosystems in India namely moist deciduous forest of Madumalai (Gokula 1998), Nelliampathy hills of Southern Western Ghats of Palakkad, Kerala and tropical evergreen forests of Silent Valley (Jayson and Mathew 2000), dry deciduous forest of Tamil Nadu (Nirmala 2002) and Tamhini, Northern Western Ghats, Pune (Anand et al. 2007).

Landscape element wise distribution pattern of birds showed highest species richness and Shannon diversity in LSE 4, which comprises mixed moist deciduous canopy, that could be due to the presence of majority of evergreen trees, which provided the sufficient food in the form of flowers and insects and low species richness and Shannon diversity index in LSE 1, which comprises bamboo vegetation, this is due to less availability of the food sources. The species richness and Shannon diversity index are found to be medium when compared to the LSE 4, and hence low birds density was evidenced in the LSE2, LSE 3, which comprised mixed dry deciduous forest that could be due to the least number of evergreen tree species. Hence they provide less food for the livestocks, when compared to LSE 4. This indicates that there was more richness and diversity in the undisturbed habitats rather than the disturbed 
habitat. The species distribution in the landscape elements will be higher unless the area is not disturbed due to forest activities.

The seasonal distribution pattern showed two peaks of species richness, Shannon diversity, equitability, and evenness index, one in early winter and the other in summer. A number of reasons, including north-south migration, breeding, food availability and vegetation changes, could be attributed to this pattern and also suspect that a few of the migrants visit Lakkavalli range forest during their north-south migration within the Indian subcontinent, which contributes to high species richness during early winter. Also, at the end of the winter these species migrate back towards north, the species richness in the summer shows another peak. Breeding pattern can have a major influence on the distribution pattern. Depending on seasonality, many species breed in late winter, which contributes to more of nesting and less of roaming in late winter and hence low sighting was revealed. On the contrary, in the spring probably eggs hatch and birds can be seen roaming as they gather food for the new born. New individuals can also contribute to high richness and diversity of spring. Flowering in the early winter assures food availability and it could also be an important cause for high species richness, while comparatively low vegetation thickness in spring and summer can also contribute to high species richness and diversity mainly due to the fact that as there is more exposure, birds can be easily sighted. Low sighting of the birds in monsoon could be due to the less activity (Anand et al. 2007).

As the study area lies within the parts of the Western Ghat, it receives heavy rain which varied from 1200 to $2600 \mathrm{~mm}$ and most of which falls during July to September through the southwest monsoon. This is a major decisive factor. It results into a hostile environment for the birds to stay. The daylight is very poor; some times the entire area may be occupied by clouds resulting into poor visibility in monsoon. Chilling winds worsen the wet conditions. These results into low species distribution and low sightings in the study area (Anand et al. 2007).

The species still remain in the study area are habitat specific ones, which can tolerate the hostile conditions and some species become secretive to reside in the dense canopy and thus can not be sited in the transects. Most of the species encountered in transacts during monsoon breed in this season. These conditions also result into meager food availability. It is evident from the study, that fruigivorous and insectivorous birds $(52 \%)$ constitute majority of the bird community in the study area. Therefore, the food availability for these birds is extremely scanty during the monsoon season. This is another reason for their less sighting and low species richness and diversity. Subsequent seasons show better food availability due to increased sunlight and temperature as well as reduction in rainfall. Insect population rises from October onwards and hence the birds start coming back. The species overlapping pattern starts getting restored. High $\alpha$ - and $\beta$-diversity during spring and summer is attributed to the availability of diverse food. Majority of the flora of study area shows flowering and fruiting during this period. The study revealed the presence of large number of nectarivorous birds (sun birds), though their number was large but the species are few in number.

As per the present study, mixed moist deciduous, and dry deciduous forests in the study area are best habitats for the birds as far as the number and diversity is concerned. As the most serious loss of the biodiversity value occurs in the transformation of original landscapes to croplands due to human interference (Pramod et al. 1997), evaluation of bird communities from various study sites from the Western Ghats is essential for planning "biodiversity-friendly" developmental activities. 


\section{ACKNOWLEDMENTS}

We are thankful to $\mathrm{Mr}$ Shridhar, ACF, Ravindranath RFO and Bhojaraj, Forester for permitting to undertake the study in Lakkavalli range forest and providing facilities during the study period.

\section{REFERENCES}

Ali, S. and S.D. Ripley. 1983. Hand Book of Birds of India and Pakistan. Oxford university press, Delhi, pp. 110-112.

Anand, D. Padhye, M. Paingankar, N. Dahanukar and S. Pande. 2007. Seasonal and landscape element wise changes in the community structure of avifauna of Tamhini, Northern Western Ghats, India. Zoo's Print Journal, 22 (9):2807-2838.

Bilgrami, K.S. 1995. Concept and Conservation of Biodiversity. CBS Publishers and distributors, Delhi.

Daniels, R.J.R., N.V. Hegde and M. Gadgil. 1992. On the relationship between birds and woody plant speicies diversity in the Uttar Kannada district of south India. Proceedings of the National Academy of Science. USA, 89:5331-5315.

Gokula, V. 1998. Bird Communities of the Thorn and Dry Deciduous Forests in Madumalai Wildlife Sanctuary, South India. Ph.D. Thesis, Bharathiar University, Coimbatore, 200 pp.

Grimmet, R., C. Inskipp and T. Inskipp. 2001. Birds of Indian Subcontinent. Oxford University Press, Delhi, 384 pp.

Jayson, E.A. and D.N. Mathew. 2000. Diversity, species abundance and distribution of birds in the tropical forests of Silent Valley, Kerala. J. Bom. Nat. Hist. Soc. 97:52-61.

Manakadan, R. and A. Pittie. 2001. Standardized common and scientific names of the birds to the Indian Sub continent. Buceros, 6(1):1-37.

Nirmala, T. 2002. Ecology of birds communities in the Anaikatty hills, Coimbatore. Ph.D. Thesis, Bharathiar University, Coimbatore, 274 pp.

Pramod, P., R.J.R. Daniels, N.V. Joshi and M. Gadgil. 1997. Evaluating bird communities of Western Ghats to plan for a biodiversity friendly development. Current Science, 78:156-162.

Robertson, H.A. and K.R. Hackwell. 1995. Habitat preferences of birds in seral kahikatea Dacrycarpus dacrydioides (Podocarpaceae) forest of South Westland, New Zealand. Biological Conservation, 71:275-280. 